\title{
Laws, norms, and the Institutional Analysis and Development framework
}

\author{
DANIEL H. COLE* \\ Maurer School of Law and School of Public \& Environmental Affairs, Indiana University, USA
}

\begin{abstract}
Elinor Ostrom's Institutional Analysis and Development (IAD) framework has been described as 'one of the most developed and sophisticated attempts to use institutional and stakeholder assessment in order to link theory and practice, analysis and policy'. But not all elements in the framework are sufficiently well developed. This paper focuses on one such element: the 'rules-in-use' (a.k.a. 'rules' or 'working rules'). Specifically, it begins a long-overdue conversation about relations between formal legal rules and 'working rules' by offering a tentative and very simple typology of relations. Type 1: Some formal legal rules equal or approximate the working rules; Type 2: Some legal rules plus (or emended by) widely held social norms equal or approximate the working rules; and Type 3: Some legal rules bear no evident relation to the working rules. Several examples, including some previously used by Ostrom, are provided to illustrate each of the three types, which can be conceived of as nodes or ranges along a continuum. The paper concludes with a call for empirical research, especially case studies and meta-analyses, to determine the relevant scope of each of these types of relations, and to provide data for furthering our understanding of how different types of rules, from various sources, function (or not) as institutions.
\end{abstract}

\section{Introduction}

The Institutional Analysis and Development (IAD) framework has been described as 'one of the most developed and sophisticated attempts to use institutional and stakeholder assessment in order to link theory and practice, analysis and policy' (Aligica, 2006: 89). But it suffers from notable weaknesses, including its failure to account for the complex relations between formal legal rules and 'rules-inuse' (or 'working rules'). The purpose of this paper is to begin a process of exploring the variable relations between legal rules and 'working rules' (a.k.a., 'rules-in-use') to enhance the IAD framework's utility.

The first section of this paper briefly reintroduces the IAD framework. The second section focuses on the role of formal and informal rules in the IAD framework. The third section offers a tentative typology of relations between formal legal rules and the 'working rules' of the game. The paper concludes with a

*Email: dancole@indiana.edu 
Figure 1. Basic Components of the IAD Framework

\section{Exogenous Variables}

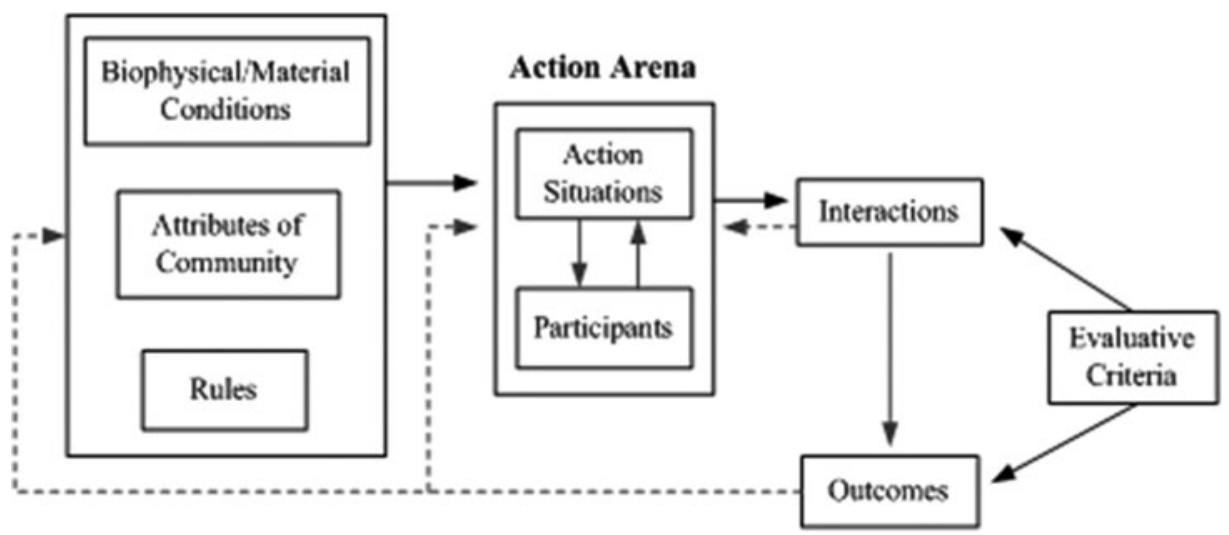

Source: Ostrom (2005, p. 15, Fig. 1.2)

call for further (qualitative as well as quantitative) empirical research concerning the relations between formal legal rules and 'working rules', including the social and legal processes that influence or determine those relations.

\section{Function and evolution of the IAD framework}

Originally developed in the 1980s by Elinor Ostrom and colleagues at the Workshop in Political Theory and Policy Analysis at Indiana University (see Kiser and Ostrom, 1982), the IAD framework as it stands today is the product of several important influences. Foremost among them are the political theories of Ostrom's husband and partner, Vincent, whose work described many of the framework's elements before the first version of the IAD was constructed. A second important influence was Elinor Ostrom's increasing engagement with game theory, especially during and after her semester studying with Reinhard Selten in Bielefeld, West Germany, in 1981. It is easy to see this influence in the very structure of the IAD (Figure 1), with actors in positions, entering into social interactions with their own strategies (as well as ethics, ideas, and information), and operating under sets of rules that structure social interactions. The 'action situation' might as well be, and sometimes is in fact, a 'decision node' in an iterated game. Just as in the theory of games, social interactions in the IAD framework produce outcomes that affect the material welfare of the actors (and potentially others).

The IAD framework evolved significantly over time. Figure 1 might be called the 'standard version', as Ostrom used it in her most complete explication of the framework (E. Ostrom 2005: 15) and regularly thereafter (e.g. E. Ostrom, 2010: 646). As in most versions of the IAD framework, the centrepiece is the 
action situation, which is an actual or virtual social forum where individuals meet and engage with one another, establishing patterns of interaction that generate outcomes for those individuals, as well as wider social and ecological effects. Actors enter action situations in positions (e.g. citizen, seller, buyer, senator, litigant, judge, etc.), with whatever cognitive capacities, information, preferences, strategies (conditional cooperator, rent-seeker, free-rider, etc.), they possess, all of which are to varying degrees shaped by existing biophysical conditions, the attributes of the community in which they live, and the 'rules'.

In this version of the framework, Ostrom refers to the variables preceding the action situation as 'exogenous'. This makes sense in so far as they are external to a given action situation. But the variables are, in fact, endogenised to the framework by virtue of the feedback loops from the Outcomes box, as patterns of interaction effecting biophysical conditions, community attributes and rules. It is, perhaps, more appropriate to think of those variables as the 'social and ecological context' within which a focal action situation arises. ${ }^{1}$

\section{Constitutional, policy, and operational levels under the IAD framework}

Among the unique features of the IAD framework is its utility across a wide range of social settings, including markets, courtrooms, corporate boardrooms, clubs, faculty meetings, religious synods and the family dinner table. It also works at all levels of social choice, including: the constitutional level, where constitutional rules are outputs that establish the meta-rules of the game; the policy-making level, ${ }^{2}$ where laws and regulations, enacted in compliance with the constitutional rules, are outputs that establish rules designed to affect individuals' interactions at the 'operational level'. In the aggregate, the daily operational-level interactions of individuals within or among communities establish 'patterns of interaction' that can affect the social-ecological context in which they occur. Indeed, choices made at each level have outcomes (in addition to outputs) that can affect the biophysical conditions, community attributes, and rules at other levels. Figure 2 illustrates the relations between levels of choice, rules and outcomes.

To illustrate the crosscurrents across levels of interaction, consider the case of 'Prohibition', a massive but doomed effort at social engineering undertaken in the United States between 1920 and 1933. The Eighteenth Amendment to the US Constitution, which took effect on 16 January 1919 (subsequently amended as of 17 January 1920), prohibited the production, transport and sale (but not the private possession or consumption) of alcohol throughout the country. It

1 One implication of this treatment is that those boxes might be replaced by the first-tier variables of Ostrom's subsequently developed SES framework (see E. Ostrom, 2007, 2009).

2 I prefer the term 'policy level' to 'collective choice level', the term usually employed by Ostrom and others using the IAD framework, because it is more specific. Constitutional-level decisions are just as much collective-choice decisions as are lower-level policy decisions. 
Figure 2. Levels of social interaction and choice

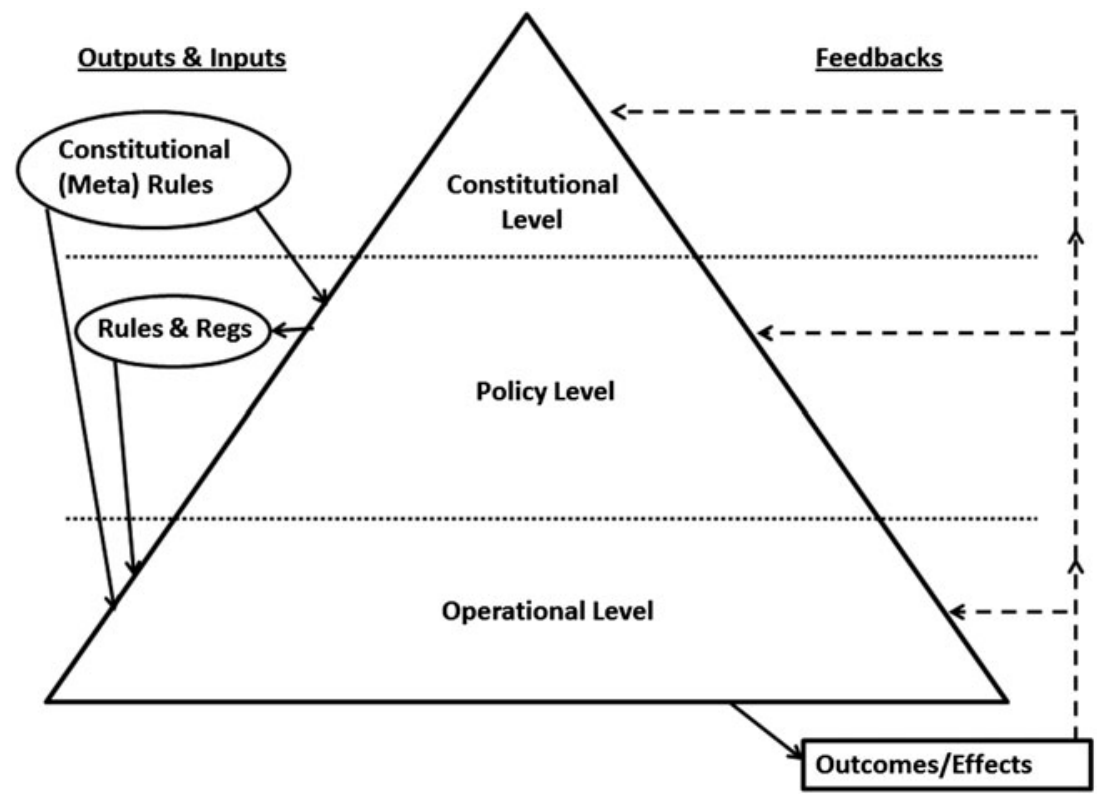

was the outcome of a 'constitutional action situation' driven by a coalition of 'Baptists and Bootleggers' (see e.g. Yandle, 1983).

The US Constitution provides two separate sets of procedural meta-rules (i.e. rules for establishing rules) for its own amendment: Under Article V, the Constitution is amended when three-quarters of the states ratify a proposed amendment enacted by two-thirds super-majorities in both houses of Congress. Alternatively, the states can amend the Constitution without congressional action, on their own initiative. Two-thirds of the states can call a constitutional convention at which amendments can be adopted by simple majority vote, subject to ratification by three-quarters of all the states. The Eighteenth Amendment was adopted pursuant to the first of these processes. It provided a constitutional meta-rule establishing Prohibition, which Congress then supplemented, in a 'policy action situation', with the Volstead Act (Pub. L. 66-s66). That statute, which survived a veto by President Woodrow Wilson (in accordance with other procedural meta-rules of the game empowering Congress to override a presidential veto upon two-thirds super-majority votes in each chamber), added precision to the 'rules of the game' governing alcohol, including certain exceptions and exemptions from the general 'meta-rule' established in the Eighteenth Amendment. ${ }^{3}$

3 Congress arguably violated the constitutional meta-rules by, in effect, amending a constitutional provision via ordinary legislation. However, it is also possible to argue that the Volstead Act merely filled-in some gaps or offered a legislative interpretation of the Eighteenth Amendment. 
Initially, compliance with Prohibition at the operational level was high (Miron and Zwiebel, 1991), but 'black markets' in alcohol soon emerged (as the 'bootleggers' had anticipated), enriching and empowering organised crime 'families', which competed with one another through the use of violence and corruption of law enforcement. These unforeseen and unintended consequences soon 'led to widespread public disenchantment with Prohibition' (Miron and Zwiebel, 1991: 2). Alcohol consumption quickly rebounded toward pre-Prohibition levels. Congress ultimately proposed a new constitutional amendment to re-legalise alcohol production and sales. The Twenty-first Amendment originated in a 'policy action situation' - Congress' February 1933 enactment of the Blaine Act, which proposed to amend the Constitution to repeal the Eighteenth Amendment. Before the year was out, three-quarters of the states had ratified the Twenty-first Amendment (in a series of constitutional action situations), thereby ending America's single greatest experiment in social engineering.

This was a case - really, a series of related action situations at constitutional, policy, and operational levels - in which higher-level rules affected action situations at lower levels, while feedback mechanisms, in turn, led to further changes in the constitutional meta-rules of the game. Simply put, one constitutional-level action situation designed to reform individual behaviour was ultimately negated by patterns of interaction at the operational level, which reflected powerful social norms. Problems arising at both the operational and policy levels led to the nullification of the Eighteenth Amendment by the Twentyfirst Amendment, in another constitutional-level action situation, which changed the meta-rules of the game to make them conform more closely to (operationallevel) social behaviour. ${ }^{4}$

It is important to understand that, in Ostrom's terminology, the IAD is neither a theory nor a model but a framework - a conceptual umbrella under which various theories and models might be deployed and tested as mechanisms for understanding, explaining or diagnosing 'social dilemmas' (see e.g. E. Ostrom, 2005: 27-9). The framework is not completely atheoretical, of course, but it represents a 'metatheoretical conceptual map' (E. Ostrom and Cox, 2010: 455) for understanding and assessing the most important elements, as assessed by the social scientist acting more or less like an examining physician, in a given collective action setting. The framework's primary purpose is to allow social scientists from various disciplinary backgrounds to organise their thinking in similar ways about social interactions (both formal and informal), as well as outcomes, prior to assessing particular cases or diagnosing specific problems. For that purpose it is eminently useful.

4 Needless to say, the history of Prohibition presented here is simplified in order to elucidate the cross-level effects of action situations at constitutional, policy and operational levels. For a less simplistic, but still concise, history of Prohibition, see Menell (1969). 
Many of the IAD framework's elements have been well developed over the years (see, most importantly, E. Ostrom, 2005 and McGinnis, 2011a), but Ostrom always considered its elements, definitions, and the overall structure of the framework to be provisional and subject to contestation, further development and even refutation. She was almost continually revising and refining the framework and its elements. The focus of this paper is on the element labelled, in various versions of the framework as 'rules' or 'rules-in-use'.

Ostrom delineated various types of rules that condition social interactions. But she wrote little about the sources of rule types; nor did she deeply explore how formal legal rules influence, and are influenced by, social norms, 'rules-in-use' or 'working rules'. ${ }^{5}$ In her most elaborate explication of the IAD framework, Ostrom (2005) devotes five chapters to rules and their analysis. She is quite careful to distinguish rule types by function, and she carefully distinguishes rules from organisations (following North, 1990). But nowhere in those five chapters does she discuss how formal legal rules and informal social norms, singly or in combination, comprise 'the rules', 'the working rules' or the 'rules-in-use'. This is not to argue that Ostrom was unaware of distinctions between legal rules, social norms, conventions, customs and other types of rule-systems. In her 'institutional grammar', co-developed with Sue Crawford (see Crawford and Ostrom, 1995; Ostrom, 2005: Chapter 5), Ostrom specifically distinguished 'rules' from 'norms', arguing that rules $=$ norms + specified sanctions. Clearly, she understood that rules come from various sources, but her main focus remained on rule functions rather than sources. Consequently, to this day the IAD element labelled 'rules' or, more often, 'rules-in-use', remains something of a black box. My purpose here is to spur a more concerted effort to understand and delineate the roles (plural) that formal legal rules play in determining 'working rules' within the IAD framework.

\section{Formal laws, rule types, and the IAD framework}

Roscoe Pound (1910) was the first scholar to distinguish between 'rules-in-form' and 'rules-in-use', though he preferred the terms 'law-in-books' and 'law-inaction'. Nevertheless, the term 'rules-in-use' is sometimes taken to imply that 'rules-on-paper' are irrelevant. For that reason, I prefer the label 'working rules' (following Commons, 1959: 531; E. Ostrom, 2005: 19; V. Ostrom, 1976: 842), or simply 'rules', which are broader terms that do not implicitly or

5 Ostrom (1990) did, of course, observe cases in which competing sets of rules interacted, as when formal (state) rule systems negated or diminished the effectiveness of informal local commonproperty/regulatory systems. Ostrom (1986) attempted explicitly to connect legislative voting outcomes and bureaucratic procedures. More generally, McGinnis (2011b: 53, 70-71) has observed that rules-inuse are themselves outputs of other action situations. But in none of these cases was the author concerned primarily with explicating in a general, or generalisable, way the cross-influences between formal laws and working rules or 'rules-in-use'. 
explicitly conflict either with informal norms or formal legal rules. Among the 'working rules', the role of formal legal institutions has been, relatively speaking, neglected in IAD elaborations and applications. In part, this is because many such applications focus on local and (relatively) informal community decisions, rather than rule making within formal legal structures. But it is important to remember that the IAD framework is intended as a general analytical tool not limited to local common-pool resource issues. And in many - perhaps the vast majority of action situations in which most actors find themselves on a daily basis, formal legal rules are an important component of the 'working rules'.

\section{What a 'rule' is}

Schlager and Ostrom (1992: 250) define 'rules' as 'generally agreed-upon and enforced prescriptions that require, forbid or permit specific actions for more than a single individual'. This statement can usefully be decomposed into two elements that together comprise a rule: (1) deontic specification, i.e. the rule must specify actions that specified actors may, must, or must not perform; and (2) levels of compliance/enforcement, i.e. the rule must be obeyed and/or enforced to some inevitably uncertain level below which it would no longer be considered a rule (see e.g. Elmes, 1966: 51) but something less, such as a standard, guideline, recommendation, ethic, signal, expression or simply an empty gesture. For the sake of conceptual clarity, the examples of rules provided in this paper intentionally steer clear of the admittedly fuzzy boundaries of both deontic specification and obeisance/enforcement.

A spectrum exists between complete non-enforcement and 100 per cent enforcement. Presumably, no one would require perfect enforcement as a defining condition for a 'rule'. For most rules, actual enforcement levels (not to mention the socially optimal level of enforcement) is far below 100 per cent (see e.g. Cole and Grossman, 2011 346-7). But the problem of under-enforcement is tricky. At some point along the enforcement continuum, between perfect non-enforcement and perfect enforcement, the actual enforcement rate could become so low that it no longer makes sense to call the rule a 'rule'. Just where that point lies seems objectively indeterminate and so inherently subjective.

\section{Formal legal rules are important for the IAD framework}

Virtually all legal scholars today appreciate that formal legal rules and processes - including court rulings, duly enacted statutes, and subsidiary regulations are not the only institutions that structure social relations. They have written about the important, sometimes dominant, roles of custom (see e.g. Ehrlich [1936] 2009: chapter 19; Smith, 2009), social norms (see e.g. Ellickson, 1991)

6 'The laws of the land share one great weakness with all other laws; they are not laws unless they are enforced.' 
and 'legal pluralism' (see Griffiths, 1986). ${ }^{7}$ By contrast, formal legal rules are sometimes derided as 'dead letters' because they are unable, by themselves, to affect behaviour (see Kingston and Caballero, 2009); or they are said to serve only an auxiliary function, 're-institutionalising' existing customary rules that arise in the first place from social norms or customs within organisations, including churches, families, communities and cultures (Bohannan, 1965: 34-7). Were that invariably the case, formal legal rules could be safely ignored without consequence. As it happens, however, formal legal rules are very often of great importance in understanding social interactions and individual behaviour.

Elinor Ostrom would not disagree. In fact, she regularly invoked formal legal rules to explicate functional rule types. Formal legal mechanisms and processes featured prominently in her works on water allocation in Southern California, beginning with her $1965 \mathrm{PhD}$ dissertation, which concerned the role of public entrepreneurs in devising groundwater management systems in California. Formal proceedings in state courts facilitated negotiations among stakeholders resulting in complex interagency agreements that were designed to ensure replenishment of groundwater supplies and prevent saltwater intrusion (see E. Ostrom, 1965; also see V. Ostrom and E. Ostrom, 1972: 8). ${ }^{8}$

Ostrom wrote a great deal about various types of rules that condition activity in action arenas (see Crawford and Ostrom, 1995, E. Ostrom, 2005: chapters 5 and 7), but she never explained how formal laws related to the 'working rules'. Table 1 describes Ostrom's rule types; and Figure 3 shows how those rules are supposed to come into play in action situations. ${ }^{9}$

Interestingly, in Understanding Institutional Diversity, Ostrom (2005: chapter 7) relies almost exclusively on formal legal rules and processes to explicate the rule types in Table 1 and Figure 3. For example, she describes 'position rules' by reference to: the US Constitution's age and citizenship conditions for membership in Congress; rules of criminal procedure requiring arrested actors to participate in court proceedings against them; and the general requirement to pay taxes

7 According to some legal pluralist theories, the legal academy is dominated by 'legal centrists' who treat state-based legal norms as dominant. Any observer of the structure of professional legal education would have to concur, which is not to concede, however, that state-based legal rules do not predominate (at least in certain societies).

8 'The structure of incentives inherent in the law of water rights is clearly not sufficient to constitute a variety of collective enterprises capable of increasing the supply of water services available to a community of water users. Such users must have access to courts, legislatures and other decision-making facilities capable of taking authoritative decisions in determining, enforcing and in altering decision-making arrangements'.

9 I am not here arguing that Ostrom's rule types constitute all possible rule types affecting action situations (there may be others) or, more importantly, that her rule types are always instituted as actual rules, under her strict definition of 'rule' (discussed above). It is easy to imagine, for example, that a player's 'position' in some focal action situation is determined by custom or tradition rather than 'rule'. Nevertheless, the various formal legal rules by which she exemplifies the rule types in Understanding Institutional Diversity are, in fact, rules on her definition. 
Table 1. Types and functions of rules in the IAD Framework

\begin{tabular}{|c|c|}
\hline Type of rule & Function of rule \\
\hline Position rules & $\begin{array}{l}\text { Create positions (e.g. member, judge, voter, representative) that actors may } \\
\text { hold. }\end{array}$ \\
\hline Boundary rules & $\begin{array}{l}\text { Define (1) who is eligible to hold a certain position, }(2) \text { the process by which } \\
\text { positions are assigned to actors (including rules of succession), and ( } 3 \text { ) how } \\
\text { positions may be exited. }\end{array}$ \\
\hline Choice rules & $\begin{array}{l}\text { Prescribe actions actors in positions must, must not, or may take in various } \\
\text { circumstances. }\end{array}$ \\
\hline Aggregation rules & $\begin{array}{l}\text { Determine how many, and which, players must participate in a given collective- } \\
\text { or operational-choice decision. }\end{array}$ \\
\hline Information rules & $\begin{array}{l}\text { Authorise channels of information flows available to participants, including } \\
\text { assignation of obligations, permissions, or prohibitions on communication. }\end{array}$ \\
\hline Payoff rules & $\begin{array}{l}\text { Assign rewards or sanctions to particular actions that have been taken or based } \\
\text { on outcomes. }\end{array}$ \\
\hline Scope rules & $\begin{array}{l}\text { Delimit the range of possible outcomes. In the absence of a scope rule, actors } \\
\text { can affect any physically possible outcomes. }\end{array}$ \\
\hline
\end{tabular}

Figure 3. Where Different Types of Rules Enter Action Situations

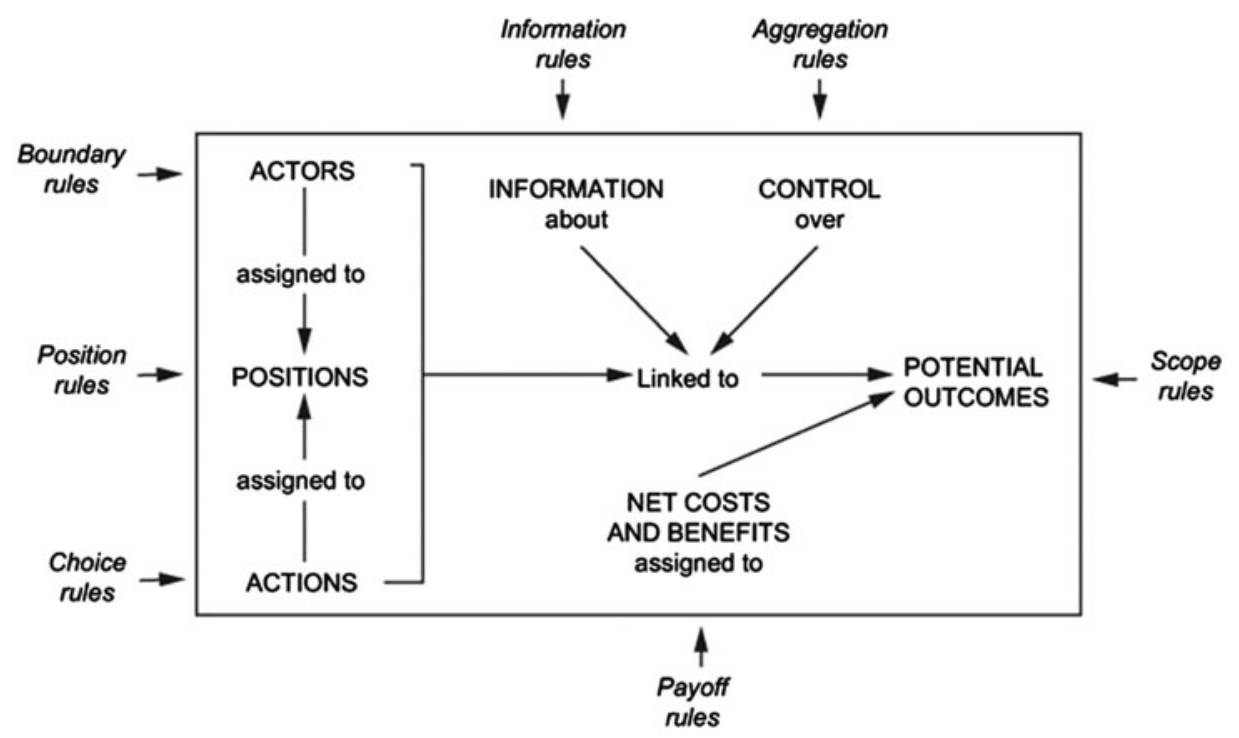

(Source: Ostrom 2005, p. 189, Fig. 7.1)

consistent with the tax code (E. Ostrom, 2005: 195-6). She illustrates 'exit rules' with legal term limits for some elective office holders and prisoners, and by reference to litigants in civil justice settings who choose to settle out of court (E. Ostrom, 2005: 198-200). 'Aggregation rules' are exemplified by formal adoption and amendment processes for legislation, a task requiring the cooperation of 
Figure 4. Relationships of formal and informal collective-choice arenas.

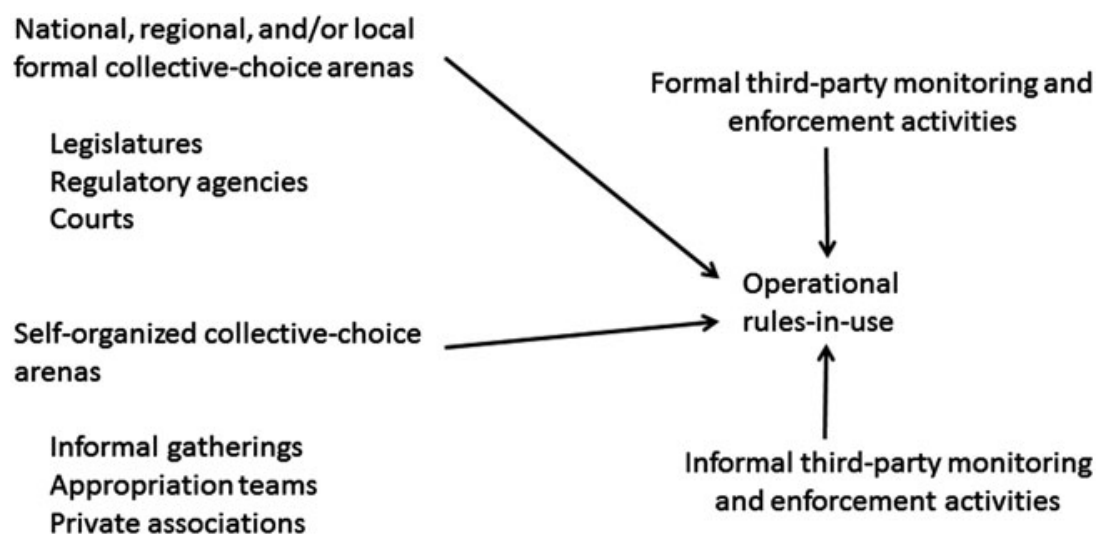

(Source: Ostrom 2005, p. 62, Fig. 2.4)

multiple legislators (E. Ostrom, 2005: 202). Ostrom explains 'payoff rules' by reference to labour contracts. And 'scope rules', she illustrates by government regulations specifying the goal to be achieved, but allowing regulated entities discretion in how best to achieve that goal (E. Ostrom, 2005: 209). This extensive reliance on formal legal rules to exemplify rule types suggests that, for Ostrom, legal rules were more than just words on paper that had no effect on operationallevel interactions. Moreover, she (Ostrom, 2005: 62, Figure 2.4) also directly related (using arrows) formal legal rules (as well as informal social norms) to '[o]perational rules in use' (see Figure 4). Nevertheless, she never explained or offered examples of processes by which those relations arise or persist.

Most tellingly, the very structure of the IAD framework, which is designed to work at different levels of social choice, suggests that formal legal rules are often (if not always) expected to play a significant role. The framework's differentiation of constitutional- and collective-level choices presupposes that the outputs of those processes - constitutional and legal rules and regulations, respectively can and do affect operational-level choices (see E. Ostrom, 2005: 214-15). Thus, the law is imbricated within the structure of the IAD framework.

Nevertheless, in the framework itself, formal legal rules appear only as generic 'rules', or more often in the somewhat loaded phrase, 'rules-in-use', which is often used (though not by Ostrom herself) in a way that denigrates formal legal rules. So, the question remains, by what process(es) and to what extent are formal legal rules translated or converted into 'rules-in-use' (or 'working rules')? This is decidedly not a question about formal institutions (laws) versus informal institutions (social norms) (see North, 1990: 3) but of how rules of any kind are understood, given effect, or operationalised within a given community. That process of translation or 'mobilisation' itself undoubtedly involves 'patterns of interaction' observed across potentially numerous and diverse action situations. 


\section{A simple typology of relations between formal laws and 'working rules'}

Relations between formal legal rules and 'working rules', as well as those between formal legal rules and informal social norms (on which see e.g. Brennan et al., 2013; Hart, 1961; Posner, 2000), are more complex and multidirectional than often is supposed. Institutionalists, both 'old' (or 'classical') and 'new', appreciate that monitoring, enforcement and sanctions are critical components of successful collective action, including for common-property management of common-pool resources, as evidenced in Ostrom's 'design principles' (E. Ostrom, 1990: 90, Table 3.1). Less well appreciated is that monitoring, enforcement and sanctioning regimes are themselves complex adaptive systems, so that relations between formal laws and rules-in-use cannot be explained simply by a casual reference to monitoring, enforcement and sanctioning. Rather, analysts must dig into the actual monitoring, enforcement and sanctioning institutions and organisations of specific cases to learn whether, and to what extent, legal rules influence or determine the 'working rules'.

This section offers a simple three-part typology of relations between formal legal rules and 'working rules': (1) the formal legal rule is the 'working rule' (2) the formal legal rule significantly influences the 'working rule' (and sometimes vice versa), and (3) the formal legal rule bears no apparent relation to the 'working rule'. To illustrate each of these categories, I adapt several of the examples Ostrom (2005: chapter 7) used to illustrate different rule types that affect action situations.

\section{Type 1 . Some legal rules $\approx{ }^{10}$ working rules}

Some legal rules are so clear and controlling (within the relevant community) that they require virtually no interpretation or conversion (via implementation) into working rules. Ostrom (2005: 195) exemplifies the notion of 'boundary rules', for example, by referring to age requirements or term limits for certain political officeholders. It is difficult to imagine a plausible theory of constitutional interpretation under which the rule that an individual must be at least 35 years old to serve as president of the United States might be interpreted to allow a 30year-old individual to serve in that position. Technically, the constitutional rule is not self-enforcing - we can imagine a case where judicial enforcement of the rule is required - but it is so close to being self-enforcing in practice that it might be said to serve as both the formal rule and the working rule (or 'rule-in-use').

Similarly, standard weights and measures, although they must be enforced from time to time against non-compliers, constitute the working rules. ${ }^{11}$ No act

10 The mathematical symbol ‘ $\approx$ ' means 'approximates' or 'nearly equals'.

11 It is worth observing, in this context, that rules establishing standard weights and measures not only structure human interactions over goods, but are themselves public goods, in the strict sense of the term. Once they are established (and they only have to be established once), standard weights and measures are non-excludable and non-rivalrous in consumption. 
of interpretation is necessary to understand rules ranging from established time zones, rules of the road requiring drivers to use the left (or right) side of the road, the designation of the length of a mile or kilometre, setting the weight of one ton or the volume of a litre. Individuals quickly learn to organise their activities around such rules and become habituated to them, almost as if they were part and parcel of their thought processes. These working rules are exactly the same as the formally institutionalised legal rules.

Many (but not all) rules in sports and games are also of this nature. In football (known as soccer among Americans), the entire ball must cross the entire goal line for a goal to be scored. There certainly are close calls in which it is difficult to determine whether a goal has in fact been scored (a problem diminished by improved goal-line technology). But such factual issues do not alter the relation between the formal rule and the working rule, which is one of identity. The rule is enforced as written, even in cases where its enforcement is difficult and/or contestable.

It might be objected that all the examples cited are relative rarities among all of the working rules in the world. That, however, is an empirical question that has hardly been raised, let alone studied systematically. Moreover, some of the rules listed above - certainly rules of the road and standard weights and measures - are among the most important rules in modern commercial societies.

\section{Type 2. Some legal rules + widely held social norms $\approx$ working rules}

Some legal rules that could be working rules if strictly enforced (like those in the preceding section) are not coextensive with the working rules because they are publicly known not to be strictly enforced and a prevalent social norm exists that, in effect, translates the formal legal rule into a different but related working rule. A prime example here, to which Ostrom sometimes referred (see e.g. E. Ostrom, 2005: 18), is the speed limit for motor vehicles on public highways. Posted speed limits represent the formal legal rules, and some motorists follow them strictly. But most motorists understand that enforcement is costly (and therefore imperfect) and that law enforcers are unlikely to pull them over unless they exceed the posted speed limit by a substantial amount. So, they follow an almost universal (at least in the United States) social norm of driving approximately five miles per hour above the posted limit (in good driving conditions).

Notice that the norm itself tells us nothing about the actual speed anyone is likely to drive on a given road - the working rule - unless we also know the posted (formal legal) speed limit. Moreover, motorists know that reliance on the working rule is not foolproof. Should a highway patrol officer choose to ticket a driver for exceeding the posted speed limit by only three miles per hour, a court of law will strictly enforce that decision, regardless of the prevailing social norm. The result would no doubt strike the unfortunate motorist as grossly unfair, but 
in case of conflict the formal legal rule would trump the working rule. ${ }^{12}$ The bottom line is that, even if the working rule is not completely determined by the law-in-form (i.e. the posted speed limit), the formal legal rule plays an important role in determining the working rule.

To take another example from the sport of soccer, a rule-in-form provides that when a player from one team kicks the ball over the touchline, the other team takes possession of the ball for a 'throw in'. In some circumstances, that formal rule simply is the working rule. But in certain well-understood circumstances, the formal rule is modified by a social norm (based on a notion of fairness or equity). So, if a player from Team A is injured on the field, and Team B kicks the ball out of play so that player can receive treatment, Team A obtains possession of the ball pursuant to the formal rule. However, in accordance with the social norm, Team A returns the ball to the possession of Team B as soon as play resumes. This situation might be viewed as an instantiation of Aristotle's injunction that general rules of law must be tempered by equity in order to do justice given the specific facts of individual cases (Aristotle, 1941, NE, Book V, Chapter 10, \$1137b12-27).

How many cases are of this type, in which the working rule combines a formal legal rule with some informal social norm(s)? Once again, that is an empirical question requiring further investigation. No basis exists for presuming that this category is insubstantial. To the contrary, this category might well prove the largest.

\section{Type 3. Some formal legal rules $\notin^{13}$ working rules}

Some subset of legal institutions play no significant role in the organisation of social behaviour because they simply do not affect social interactions; indeed, some of them are not even intended to do so, being in the nature of precatory or symbolic acts. An example would be a law establishing an official state bird or tree.

In other cases, laws that are intended to have an impact on social behaviour simply fail, as we saw earlier with the case of Prohibition in the United States. Robert Ellickson's (1991) famous book, Order without Law, presents another well-known case in point. California state law generally required cattle ranchers to 'fence in' their cattle, in order to prevent them from damaging neighbouring properties or wandering onto public highways. But Shasta County, by special exemption, was allowed to adopt a bifurcated rule. Cattle ranchers in some parts of the county were subject to the general state law of 'fencing in'. But in other

12 There are of course special cases, such as where a motorist might bribe the police officer to avoid enforcement of the speed limit (whether the formal limit or the normal limit), but I am writing here about generalities, not special cases. Where bribery is not a special case but reflects, instead, a regular 'pattern of interaction', that obviously implies that the rules-in-form are related only in a more attenuated way (if at all) to the working rules.

13 The mathematical symbol ' $\notin$ ' means 'is not an element of (or in)'. 
sections of the county cattle ranchers could let their cattle roam free. In those sections, if a neighbour wanted to avoid property damage from wandering cattle, she had to 'fence out' the cattle. Obviously, these alternative rules were about cost allocation between cattle ranchers and their neighbours. Under a legal rule of 'fencing in', the cattle rancher bears the costs; under the rule of 'fencing out', neighbouring landowners bear the cost.

What Ellickson discovered when he went to Shasta County to conduct empirical research was that virtually no one abided by either of the alternative legal rules. In fact, they did not know the legal rules and, somewhat more surprisingly, neither did local lawyers who were sometimes called upon to help resolve disputes. However, in most cases disputes did not arise or did not long persist because local residents (with a few notable exceptions) ${ }^{14}$ - including cattle ranchers, crop farmers, and others - operated under a strong social norm of neighbourliness, according to which neighbours cooperated, sharing the costs of fencing cattle out or in.

In Ellickson's case, a strong and effective social norm obviated and displaced the formal legal rules adopted by the county (pursuant to state law). But how generalisable is Ellickson's case? In the absence of many similar studies, we cannot even conduct a meta-analysis to help us answer that question. What we require is a great deal more empirical research. In the absence of that research, we cannot reliably conclude that strong social norms are generally more important or more influential than formal legal rules.

Just as importantly, the supposed dichotomy of social norms versus laws might generally be the wrong way to think about relations between those two categories of institutions. ${ }^{15}$ As already established, formal laws often influence or even determine working rules. At the same time, it is clear that social norms often influence the substance of formal laws. So, for example, the unofficial norms regarding water use adopted by miners during the California gold rush (1850s) were subsequently recognised in courts of law (Hicks $v$. Bell, 3 Cal 219 (1853); Irwin v. Phillips, 5 Cal 140 (1855)), then codified into state law (Civil Code of the State of California 268-70 (1872)), and ultimately constitutionalised (see Debates and Proceedings of the Constitutional Convention of the State of California 482 (1880)).

In the somewhat similar context of irrigation rules, Insa Theesfeld (2004: 253) finds a dynamic relationship between formal rules and 'rules-in-use' that, sometimes at least, can lead to an ever-increasing reduction in the relevance of

14 Some outliers existed, but they were dealt with, usually to good effect, by social sanctions, including as a last resort ostracism.

15 Brennan et al. (2013: 51), for example, distinguish formal and non-formal norms along dimensions, including (1) the mechanisms by which they are created, (2) the mechanisms by which they are enforced, (3) de re $v$. de dicto 'normative attitudes', and (4) effects on actions versus effects on actions, attitudes and modes of deliberation. 
the formal rules, followed eventually by their eventual replacement with new formal rules:

First, rules-in-use pave the way for opportunistic strategies. The opportunistic strategies in turn change the rule-in-use, and the incongruity between formal and effective rules increases. Because of the higher incongruity, possibilities for opportunistic strategies increase once again. Second, opportunistic strategies appear and, in response, a certain rule-in-use develops. This effective rule is not congruent with the formal rule. The incongruity increases and the possibilities for opportunistic strategies increase once again. Finally, in the long run, growing incongruity enables a feedback that influences the development of the formal rules.

Theesfeld's account of how 'opportunistic strategies' alter 'rules-in-use' and, ultimately, formal rules is, once again, congruent with the history of Prohibition in the United States. Moreover, the kind of strategic opportunism highlighted in her treatment of formal rules and 'rules-in-use' is very much present in the IAD framework's 'Community Attributes' box (see Figure 1). Actors enter into action situations in various positions (citizen, corporate CEO, lobbyist, fundraiser, legislator, law enforcer, judge, etc.), possessing whatever powers and strategies. The implication, as I suggested earlier, is that the various processes by which formal rules are transformed into working rules are themselves action situations, including law enforcement and other action situations in which legal rules are evaluated and/or interpreted. It is the 'pattern of interactions' resulting from those situations that ultimately determines (1) what the working rules are (2) whether those rules deviate significantly from the formal rules, and (3) the extent of any such deviation. Importantly, Theesfeld (2004) does not presume a high level of 'incongruity' between formal rules and 'rules-in-use'. That is, after all, an empirical question.

When a particular legal rule appears to have no bearing on a particular working rule, we should not assume that the working rule is superior or more desirable. Some social norms are inefficient, morally abhorrent, resistant to change $^{16}$ or all of the above. After the US Civil War, social norms of racism gave rise to state laws that perpetuated the oppression of former slaves, despite their supposedly superior constitutional rights under the newly enacted and ratified Fourteenth and Fifteenth Amendments to the US Constitution. Indeed, the Fourteenth Amendment's Equal Protection Clause went virtually unenforced before the turn of the twentieth century, and the last vestiges of official 'Jim Crow' were not extirpated in the southern United States until passage of the Civil Rights Act in 1964 and the Voting Rights Act in 1965 (see generally Woodward [1955] 2002, Ackerman 2014). ${ }^{17}$

16 Leach and Lowndes (2007: 186) observe that 'informal rules may prove especially tenacious and resistant to change, existing in parallel - or even direct contradiction - to formal rules'.

17 Unofficial vestiges of 'Jim Crow' persist to the present day (see e.g. Bodo, 2011). 
In the case of civil rights for African Americans, the deplorable social norms were so powerful that they could not simply or easily be displaced even by a strong constitutional rule with inconsistent and ineffectual federal enforcement efforts. Eventually, over a long period of time, they were eroded (but still not eradicated) by a combination of: legal processes, including court decisions like Brown v. Board of Education, 347 US 483 (1954); policy decisions, for instance racial integration of the military in 1948 by Executive Order of the President; ${ }^{18}$ as well as less formal political and social pressures. This goes to show that, in some cases at least, 'opportunistic strategies' of opposition may prevail for some time but ultimately be subdued by consistent enforcement of countervailing formal legal rules.

Even in less politically divisive circumstances of incremental law reform, changes in formal rules are often 'filtered' by those charged with implementing or carrying out the reforms. The result can be institutional changes that are 'differentially interpreted, mediated and (in some cases) neutralized' (Lowndes and Leach, 2004: 559). Thus, in a series of case studies of implementation of the UK's Local Government Act of 2000, Lowndes and Leach (2004) found that local government authorities overwhelmingly implemented the reform law in ways that minimised the total amount of change.

The three types of relations between formal legal rules and 'working rules' described in this paper can be conceived as ranges along a continuum, with Type 1 and Type 3 at either end and Type 2 in the middle. The problem, of course, is that such a stylised continuum gives us no real clue as to the actual roles that each of the three types of relations between formal rules and working rules play in real-world action situations. For that, we require multiple empirical studies and meta-analyses of cases involving each type of relation. It is simply not enough to extrapolate from a few discrete cases that formal legal rules are all that matter, are part of what matters, or that they do not matter at all.

\section{Conclusion}

Perhaps because Elinor Ostrom most often used the IAD framework to study small-scale communities that successfully established working rules to selfgovern local common-pool resources, she did not spend much time studying how and to what extent formal legal rules influence 'rules-in-use'. ${ }^{19}$ But she intended the IAD as a general framework for diagnosing and possibly predicting collective action, including in dynamic settings. It was not designed only to diagnose local

18 Executive Order 9981, 3 CFR 722 (1948).

19 She did, however, observe cases where 'formal rules' prevented effective management of local common-pool resources by delegating insufficient authority to local users (see e.g. E. Ostrom, 1995: 39). Even then, it was not the existence of formal rules per se that was the problem. 
common-pool resource issues, where formal legal rules might be expected to play a limited role.

Even in local common-property regimes, rules often are codified and more or less formal mechanisms established for monitoring and enforcing compliance. When a group of fishers establishes a common-property regime along with rules regulating who can fish where and when, those rules often are formalised in writing and supported by other institutions for monitoring, enforcement and sanctioning (see e.g. Berkes, 1986). Many local fisheries' management schemes are highly sophisticated - much more like formal legal rules or corporate bylaws than informal social norms.

The clearest evidence that Ostrom expected formal legal rules to play a significant role in IAD settings comes from the framework itself, which she employed at constitutional and policy levels of collective choice, where formal rules (and meta-rules) come from. And, when she parsed different kinds of 'rulesin-use' in her most in-depth treatment of the IAD framework in Understanding Institutional Diversity, she relied almost exclusively on formal legal rules to exemplify them.

Given all that, it seems that formal legal rules should play a more substantial role in studies employing the IAD framework than they have done so far. Case studies and meta-analyses, especially those focusing beyond small, localised groups of resource users, would benefit from attending more carefully to how often, how many, and simply how various types of formal rules are constituted in action situations and, in turn, how those formal rules interact with informal norms to influence (or not) patterns and outcomes at collective-choice or operational levels of interaction. Such investigations would open up the black box of 'rules' in the IAD framework, allowing potentially further decomposition of variables and more finely grained analyses.

\section{Acknowledgements}

I am grateful for helpful comments during the drafting of this paper to colloquia participants at Indiana University's Ostrom Workshop and participants in conferences sponsored by the Society for Environmental Law and Economics, WINIR, and Humboldt University. Two anonymous referees provided constructive criticisms and questions that substantially improved the final product. I remain exclusively responsible for any errors.

\section{References}

Ackerman, B. (2014), We the People: Volume 3: The Civil Rights Revolution, Cambridge, MA: Belknap Press. 
Aligica, P. D. (2006), 'Institutional and stakeholder mapping: frameworks for policy analysis and institutional change', Public Organization Review 6: 79-90.

Aristotle (1941), 'Nicomachean ethics', in The Basic Works of Aristotle, translated by R. McKeon, New York: Random House, pp. 927-1112.

Berkes, F. (1986), 'Local-level management and the commons problem', Marine Policy 10(3): 215-29.

Bodo, L. D. (2011), 'Somewhere between Jim Crow and post-racialism: reflections on the racial divide in America today', Daedalus 140: 11-36.

Bohannan, P. (1965), 'The differing realms of the law', American Anthropologist 67(6): 3342.

Brennan, G., L. Eriksson, R. E. Goodin and N. Southwood. 2013. Explaining Norms, Oxford: Oxford University Press.

Cole, D. H. and P. Z. Grossman (2011), Principles of Law and Economics, 2nd edition, New York: Wolters Kluwer.

Commons, J. R. (1959), Legal Foundations of Capitalism, Madison, WI: University of Wisconsin Press.

Crawford, S. E. S. and E. Ostrom (1995), 'A grammar of institutions', American Political Science Review 89(3): 582-600.

Ehrlich, E. ([1936]2009), Fundamental Principles of the Sociology of Law, New Brunswick, NJ: Transaction Publishers.

Ellickson, R. C. (1991), Order without Law: How Neighbors Settle Disputes, Cambridge, MA: Harvard University Press.

Elmes, F. (1966), 'Government and people: III: when is a law not a law?' Police Journal 39: 47-54.

Griffiths, J. (1986), 'What is legal pluralism?' Journal of Legal Pluralism and Unofficial Law 32: $1-55$.

Hart, H. L. A. (1961), The Concept of Law, Oxford: Clarendon Press.

Kingston, C. and G. Caballero (2009), 'Comparing theories of institutional change', Journal of Institutional Economics 5(2): 151-80.

Kiser, L. L. and E. Ostrom. (1982), 'The three worlds of action: a metatheoretical synthesis of institutional approaches', in E. Ostrom (ed.), Strategies of political inquiry, Beverly Hills, CA: Sage, pp. 179-222.

Leach, S. and V. Lowndes (2007), 'Of roles and rules: analyzing the changing relationship between political leaders and chief executives in local government', Public Policy \& Administration 22(2): 183-200.

Lowndes, V. and S. Leach (2004), Understanding Local Political Leadership: Constitutions, Contexts and Capabilities', Local Government Studies 30(4): 557-75.

McGinnis, M. D. (2011a), 'An Introduction to the IAD and the Language of the Ostrom Workshop: A Simple Guide to a Complex Framework', Policy Studies Journal 39(1): 169-83.

McGinnis, M. D. (2011b), 'Networks of Adjacent Action Situations in Polycentric Governance', Policy Studies Journal 39(1): 51-78.

Menell, S. J. (1969), 'Prohibition: A Sociological View', Journal of American Studies 3(2): 159-75.

Miron, J. A. and J. Zwiebel (1991), 'Alcohol Consumption during Prohibition', American Economic Review 81(2): 242-7.

North, D. C. (1990), Institutions, Institutional Change, and Economic Performance, New York: Cambridge University Press. 
Ostrom, E. (1965). 'Public Entrepreneurship: A Case Study in Ground Water Basin Management', Dissertation, University of California, Los Angeles, CA, USA, http://dlc. dlib.indiana.edu/dlc/bitstream/handle/10535/3581/eostr001.pdf?sequence $=1$.

Ostrom, E. (1986), 'Multiorganizational Arrangements and Coordination: An Application of Institutional Analysis', in F. X. Kaufmann, G. Majone and V. Ostrom (eds), Guidance, Control, and Evaluation in the Public Sector, New York: De Gruyter, pp. 495-510.

Ostrom, E. (1990), Governing the Commons: The Evolution of Institutions for Collective Action, New York: Cambridge University Press.

Ostrom, E. (1995), 'Designing Complexity to Govern Complexity', in S. Hanna and M. Munasinghe (eds), Property Rights and the Environment: Social and Ecological Issues, New York: Beijer International Institute for Ecological Economics and World Bank, pp. 33-45.

Ostrom, E. (1999), 'Institutional Rational Choice: An Assessment of the Institutional Analysis and Development Framework', in P.A. Sabatier (ed.) Theories of the Policy Process, Boulder CO: Westview Press, pp. 35-71, at 60.

Ostrom, E. (2005), Understanding Institutional Diversity, Princeton, NJ: Princeton University Press.

Ostrom, E. (2007), 'A Diagnostic Approach for Going beyond Panaceas', Proceedings of the National Academies of Sciences 104(39): 15,181-7.

Ostrom, E. (2009), 'A General Framework for Analyzing Sustainability of Social-ecological Systems', Science 325(5939): 419-22.

Ostrom, E. (2010), 'Beyond Markets and States: Polycentric Governance of Complex Economic Systems', American Economic Review 100(3): 641-72.

Ostrom, E. and M. Cox (2010), 'Moving beyond Panaceas: A Multi-tiered Diagnostic Approach for Social-ecological Analysis', Environmental Conservation 37(4): 451-63.

Ostrom, V. (1976), 'John R. Commons' Foundations for Policy Analysis', Journal of Economic Issues 10(4): 839-57.

Ostrom, V. and E. Ostrom (1972), 'Legal and Political Conditions of Water Resource Development', Land Economics 48(1): 1-14.

Posner, E. (2000), Law and Social Norms, Cambridge, MA: Harvard University Press.

Pound, R. (1910), 'Law in Books and Law in Action', American Law Review 44(1): 12-36.

Schlager, E. and E. Ostrom (1992), 'Property-rights Regimes and Natural Resources: A Conceptual Analysis', Land Economics 68(3): 249-62.

Smith, H. E. (2009), 'Community and Custom in Property', Theoretical Inquiries in Law 10: $5-41$.

Theesfeld, I. (2004), 'Constraints on Collective Action in a Transitional Economy: The Case of Bulgaria's Irrigation Sector', World Development 32(2): 251-71.

Woodward, C. V. ([1955]2002), The Strange Career of Jim Crow, Oxford, UK: Oxford University Press.

Yandle, B. (1983), 'Bootleggers and Baptists: The Education of a Regulatory Economist', Regulation, https://techliberation.com/wp-content/uploads/2010/12/v7n3-3.pdf. 